\title{
Quantification of Epigenetic and Genetic 2nd Hits in CDH1 During Hereditary Diffuse Gastric Cancer Syndrome Progression
}

\author{
CARLA OLIVEIRA, ${ }^{*, \neq}$ SÓNIA SOUSA, ${ }^{*}$ HUGO PINHEIRO, ${ }^{*}$ RACHID KARAM, ${ }^{*, *, \S}$ RENATA BORDEIRA-CARRIÇO, ${ }^{*}$ \\ JANINE SENZ," PARDEEP KAURAH," JOANA CARVALHO, ${ }^{*}$ RUI PEREIRA, ${ }^{*,}$, LEONOR GUSMÃO, ${ }^{*}$ XIAOGANG WEN, ${ }^{*}$

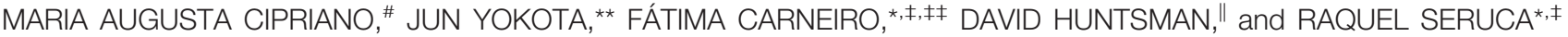 \\ *Institute of Molecular Pathology and Immunology, University of Porto (IPATIMUP), Porto, Portugal; ${ }^{*}$ Faculty of Medicine, University of Porto, Porto, Portugal; \\ ${ }^{\circledR}$ Biochemistry and Molecular Biology Department, University of Texas M.D. Anderson Cancer Center, Houston, Texas; "Hereditary Cancer Program, British Columbia \\ Cancer Agency, Vancouver, Canada; "Institute of Legal Medicine, University of Santiago de Compostela, Santiago de Compostela, Spain; "Department of Pathology, \\ Coimbra University Hospital, Coimbra, Portugal; * *Biology Division, National Cancer Centre Research Institute, Tokyo, Japan; \#¥Hospital de S. João, Porto, Portugal
}

Background \& Aims: Hereditary diffuse gastric cancer (HDGC) families carry CDH1 heterozygous germline mutations; their tumors acquire complete $\mathrm{CDH} 1$ inactivation through "2nd-hit" mechanisms. Most frequently, this occurs via promoter hypermethylation (epigenetic modification), and less frequently via $\mathrm{CDH} 1$ mutations and loss of heterozygosity ( $\mathrm{LOH})$. We quantified the different 2nd hits in $\mathrm{CDH} 1$ occurring in neoplastic lesions from HDGC patients. Methods: Samples were collected from 16 primary tumors and 12 metastases from 17 patients among 15 HDGC families; CDH1 mutations, LOH, and promoter hypermethylation were analyzed. E-cadherin protein expression and localization were determined by immunohistochemistry. Results: Somatic $\mathrm{CDH} 1$ epigenetic and genetic alterations were detected in lesions from $80 \%$ of HDGC families and in $75 \%$ of all lesions analyzed $(21 / 28)$. Of the 28 neoplastic lesions analyzed, promoter hypermethylation was found in $32.1 \%$, $\mathrm{LOH}$ in $25 \%$, both alterations in $17.9 \%$, and no alterations in $25 \%$. Half of the $C D H 1$ 2nd hits in primary tumors were epigenetic modifications, whereas a significantly greater percentage of $2 \mathrm{nd}$ hits in metastases were LOH $(58.3 \%$; $P=$ .0274). Different neoplastic lesions from the same patient frequently displayed distinct 2 nd-hit mechanisms. Different 2nd-hit mechanisms were also detected in the same tumor sample. Conclusion: The 2nd hit in $\mathrm{CDH} 1$ frequently occurs via epigenetic changes in HDGC primary tumors and LOH in metastases. Because of the concomitance and heterogeneity of these alterations in neoplastic lesions and the plasticity of hypermethylated promoters during tumor initiation and progression, drugs targeting only epigenetic alterations might not be effective, particularly in patients with metastatic HDGC.

G astric cancer is the 4th most common malignancy worldwide, although in recent decades a decline has been observed in its incidence and mortality. ${ }^{1,2}$ Diffuse gastric cancer accounts for about $30 \%$ of all gastric carcinomas and somatic mutations in E-cadherin $(C D H 1$ gene), an adhesion molecule and a tumor suppressor protein, were found in $>50 \%$ of these cases. ${ }^{3,4}$ Inactivating $\mathrm{CDH} 1$ mutations were also described in the germline of families with hereditary diffuse gastric cancer (HDGC; OMIM No. 137215), an autosomal-dominant disease characterized by clustering of early onset documented diffuse gastric cancer. ${ }^{5,6}$ So far, 82 of these families were found to carry 65 different $\mathrm{CDH} 1$ inactivating germline mutations; $83.1 \%$ are predicted to generate truncated E-cadherin transcripts (nonsense, splice-site, and frameshift mutations), and $16.9 \%$ are missense mutations. 7,8

The diminished or absent E-cadherin immunoreactivity observed in diffuse gastric cancer cells (hereditary and sporadic) harboring $C D H 1$ mutations, is consistent with biallelic $C D H 1$ inactivation by a 2 nd-hit mechanism leading to E-cadherin loss, and determining diffuse cancer development. ${ }^{9-13}$ In sporadic diffuse gastric carcinomas harboring somatic CDH1 mutations, promoter methylation was the most frequently found 2 nd-hit inactivation mechanism. ${ }^{13}$

To date, tumors from 13 of 82 (15.9\%) HDGC families harboring $\mathrm{CDH} 1$ germline mutations were analyzed for CDH1 2nd-hit inactivation mechanisms. ${ }^{10-12,14}$ Apart from the low number of cases analyzed, a single neoplastic lesion was investigated per patient, which constitutes a clear drawback in the analysis, because HDGC is a disease with multiple and apparently unrelated tumor foci, scattered in the stomach of mutation carriers. ${ }^{15,16}$ Data from 27 tumors arising in 27 patients from the 13 HDGC families studied so far still indicate $C D H 1$ promoter hypermethylation as the most common 2nd-hit mechanism of inactivation. ${ }^{10,11,14}$ In contrast with studies on the 2nd-hit inactivation mechanism of genes causing other neoplastic syndromes, ${ }^{17-20}$ somatic genetic alterations (mutations and loss of heterozygosity $[\mathrm{LOH}]$ ) of

\footnotetext{
Abbreviations used in this paper: HDAC, histone deacetylase; HDGC, hereditary diffuse gastric cancer; IHC, immunohistochemistry; LOH, loss of heterozygosity; PCR, polymerase chain reaction.

(1) 2009 by the AGA Institute 0016-5085/09/\$36.00 doi:10.1053/j.gastro.2009.02.065
} 
CDH1 were uncommonly found. ${ }^{10-12,14}$ As a consequence, $\mathrm{CDH} 1$ promoter hypermethylation has been suggested as the basis for development of early detection tools as well as for chemoprophylaxis in unaffected $C D H 1$ mutation carriers. ${ }^{21}$

Among many anticancer drugs collectively named "targeted or molecular therapies," epigenetic drugs constitute an attractive possibility for disease control, because they inhibit histone deacetylases (HDAC) and DNA methyltransferases, leading to gene re-expression. $\mathrm{CDH} 1$ gene became demethylated and selectively re-expressed in human cancer cell lines upon treatment with the histone deacetylation inhibitor trichostatin $\mathrm{A},{ }^{22}$ raising the hypothesis that such a treatment would benefit HDGC patients. This therapeutic approach would have a clinical and therapeutic limitation in HDGC patients presenting with tumors harboring somatic $\mathrm{CDH} 1$ mutations or $\mathrm{LOH}$ as the 2nd-hit inactivation mechanism.

We decided to characterize the 2 nd-hit in 28 neoplastic lesions (16 primary and 12 metastases) from $17 \mathrm{CDH} 1$ germline mutation carriers belonging to 15 different HDGC families, to understand the clinical potential of epigenetic drugs in the therapeutic management of HDGC patients. Moreover, it is also our aim to clarify whether different neoplastic lesions from the same individual display different 2nd-hit inactivation mechanisms. Our study encloses the largest series of HDGC tumors from families harboring $C D H 1$ germline mutations analyzed so far, and our results demonstrate that not all HDGC patients are likely to benefit, in the near future, from epigenetic pharmacologic therapies.

\section{Materials and Methods}

\section{Patients and Samples}

Twenty-eight neoplastic foci from 17 individuals from 15 HDGC families carrying distinct $C D H 1$ mutations and fulfilling the International Gastric Cancer Linkage Consortium criteria ${ }^{23}$ were selected for analysis: (1) $\geq 2$ documented cases of diffuse gastric cancer in 1 st-/2nd-degree relatives, with $\geq 1$ diagnosed before the age of 50 ; or $(2) \geq 3$ cases of documented diffuse gastric cancer in $1 \mathrm{st}-/ 2 \mathrm{nd}$-degree relatives, independent of age. The study protocol was reviewed and approved by the appropriate ethics committees. Family histories were obtained with informed consent. Family history, $C D H 1$ germline mutation status, and representative paraffinembedded material from tumor and normal gastric mucosa were obtained from the British Columbia Cancer Agency in Vancouver, Canada ( $n=11$ individuals), from the Department of Clinical Genetics of Santa Casa de Portalegre, Brazil ( $n=1$ individuals); from the National Cancer Center Research Institute, Tokyo, Japan $(n=1$ individual); from Hospital de S. Joao, Porto, Portugal $(n=2$ individuals); from Coimbra University Hospital,
Coimbra, Portugal ( $\mathrm{n}=1$ individual); and from the First Affiliated Hospital of Zhengzhou University, Zhengzhou, China ( $n=1$ individual). Twenty-eight neoplastic foci were analyzed, 16 were representative of primary tumors (14 gastric and 2 colorectal), and 12 were representative of metastatic foci ( 2 localized in the peritoneum, 5 in lymph nodes, 1 in the colon mesentery, 1 in the small bowel mesentery, and 3 in the ovary; Table 1).

Hematoxylin and eosin-stained, $4 \mu \mathrm{m}$ sections from each case were used to label tumor and normal mucosa. Sections of 5-10 $\mu \mathrm{m}$ were used to macrodissect tumor and normal mucosa. High molecular weight DNA was isolated from paraffin-embedded tissue using the Invisorb Spin Tissue Mini Kit (Invitek, Berlin, Germany) following the manufacturer's instructions. DNA extracted from macrodissected areas with $\geq 75 \%$ of neoplastic cells, identified by an experienced pathologist (FC), was used to characterize molecular alterations in tumor DNA in comparison with DNA extracted from matched normal mucosa.

\section{CDH1 Mutation Screening and $\mathrm{LOH}$ Analysis}

After DNA extraction from tumor and normal mucosa, 30 ng of template DNA was used in 2 multiplex polymerase chain reaction (PCR) reactions. Reaction 1 was performed with a primer set to amplify the exon where the $C D H 1$ germline mutation lays (to exclude contamination with other samples) and 4 primer sets to amplify exons 7-10 where somatic mutations commonly cluster. Reaction 2 was performed with a primer set to amplify the exon where the $C D H 1$ germline mutation lays and 2 primer sets to amplify $\mathrm{CDH} 1$ common polymorphisms (the promoter $-160 \mathrm{C} / \mathrm{A}$ transvertion [rs16260] and a silent substitution $2076 \mathrm{C} / \mathrm{T}$ at exon 13 [rs1801552]) that were used as intragenic markers for $\mathrm{LOH}$ analysis. In cases where these polymorphisms were homozygous, and, whenever possible, another silent substitution at exon 14 (2253C/T [rs33964119]) was used. From these 2 multiplex PCR products, of not $>35$ cycles each, we used $20 \mathrm{ng}$ to specifically and separately re-amplify each of the aforementioned amplicons. After this 2nd round of amplification, PCR products were run and excised from agarose gels, purified, and sequenced. To analyze $\mathrm{LOH}, 3$ proximal and distal microsatellite markers (D16S3025, D16S496, D16S3067) flanking the CDH1 locus were amplified, in a multiplex fluorescent PCR and run on a ABI3100 Genetic Analyzer, from tumor and matched normal mucosa samples. All experiments were repeated at least twice using paraffin DNA as template. Only informative markers were considered for $\mathrm{LOH}$ analysis: A sample harboring a reduction in the pick area of 1 allele of $\geq 90 \%$, in comparison to the other allele, was considered to display LOH. 
Table 1. Clinical and Molecular Data From HDGC Families and Patients Analyzed for 2nd-Hit Mechanisms Affecting the CDH1 Gene

\begin{tabular}{|c|c|c|c|c|c|c|}
\hline Family ID & Patients & Age & Tissue type & Neoplastic lesion site & Germline mutation & Germline mutation type \\
\hline $1^{35}$ & 1 & 39 & Tumor Foci 1 & Stomach & $283 C>T$ & Nonsense \\
\hline \multirow[t]{3}{*}{$2^{36}$} & 1 & 32 & Tumor Foci 1 & Stomach & 382delC & Frameshift \\
\hline & 1 & & Metastasis 1 & Peritoneum & & Frameshift \\
\hline & 1 & & Metastasis 2 & Peritoneum & & Frameshift \\
\hline \multirow[t]{2}{*}{$3^{37}$} & 1 & 67 & Metastasis 1 & Small bowel mesentery & $1003 C>T$ & Nonsense \\
\hline & 2 & 57 & Tumor Foci 1 & Stomach & & Nonsense \\
\hline \multirow[t]{7}{*}{$4^{6}$} & 1 & 38 & Tumor Foci 1 & Colorectum & $1018 A>G$ & Missense \\
\hline & 1 & & Tumor Foci 2 & Colorectum & & Missense \\
\hline & 1 & & Metastasis1 & Pericolic lymph node & & Missense \\
\hline & 2 & 47 & Tumor Foci 1 & Stomach & $1018 A>G$ & Missense \\
\hline & 2 & & Tumor Foci 2 & Stomach & & Missense \\
\hline & 2 & & Metastasis 1 & Perigastric lymph node & & Missense \\
\hline & 2 & & Metastasis 2 & Perigastric lymph node & & Missense \\
\hline $5^{37}$ & 1 & 28 & Tumor Foci 1 & Stomach & 1063delT & Frameshift \\
\hline \multirow[t]{5}{*}{$6^{38}$} & 1 & 28 & Tumor Foci 1 & Stomach & $1137 \mathrm{G}>\mathrm{A}$ & Splicing \\
\hline & 1 & & Tumor Foci 2 & Stomach & & Splicing \\
\hline & 1 & & Metastasis 1 & Ovary & & Splicing \\
\hline & 1 & & Metastasis 2 & Ovary & & Splicing \\
\hline & 1 & & Metastasis 3 & Ovary & & Splicing \\
\hline $7^{36}$ & 1 & 51 & Tumor Foci 1 & Stomach & $1225 \mathrm{~T}>\mathrm{C}$ & Missense \\
\hline $8^{36}$ & 1 & 34 & Metastasis 1 & Colon mesentery & 1476del(AG) & Frameshift \\
\hline $9^{36}$ & 1 & 42 & Tumor Foci 1 & Stomach & 1779insC & Frameshift \\
\hline $10^{39}$ & 1 & 23 & Tumor Foci 1 & Stomach & $1901 C>T$ & Missense/Splicing \\
\hline $11^{36}$ & 1 & 24 & Tumor Foci 1 & Stomach & 2061delTG & Frameshift \\
\hline $12 *$ & 1 & 28 & Metastasis 1 & Lymph node & $2195 \mathrm{G}>\mathrm{A}$ & Missense/Splicing \\
\hline $13^{35}$ & 1 & 39 & Metastasis 1 & Lymph node & 2398delC & Frameshift \\
\hline $14^{40}$ & 1 & 56 & Tumor Foci 1 & Stomach & $2494 G>A$ & Missense \\
\hline $15^{41}$ & 1 & 38 & Tumor Foci 1 & Stomach & $2269 G>A$ & Missense \\
\hline
\end{tabular}

*Unpublished family results.

\section{CDH1 Promoter Methylation Analysis}

We analyzed $12 \mathrm{CpG}$ sites within the 90 base pairs upstream of the CDH1 translation start site (ATG). Owing to DNA amount limitations, we restricted the study of $\mathrm{CDH1}$ promoter methylation status to this fraction of $\mathrm{CpG}$ sites from $\mathrm{CPG}$ island 3 , because methylation at this location is commonly associated with E-cadherin expression loss. Moreover, this CPG island has been described as a hallmark of promoter methylation in human cancers. ${ }^{24,25}$ CDH1 promoter methylation analysis was performed in all tumor DNA samples. The EpiTect Bisulfite Kit (Qiagen, Valencia, Calif) was used to treat $200 \mathrm{ng}$ of DNA. Unmethylated cytosines were converted to uracil, whereas methylated ones remained unmodified. Bisulfite treated DNA from white blood cells was in vitro methylated with M.SssI DNA MeTase and used as a positive control for methylation determination. The region encompassing $12 \mathrm{CPG}$ sites was PCR amplified using flanking primers (sequences available upon request), specifically designed for bisulfite treated DNA sequences without $\mathrm{CPG}$ sites, and sequenced for methylation status determination. Re-amplification of the products was performed whenever recurrent failure in the 1st-round PCR occurred. Independent PCR amplifications were performed at least twice for each sample. Neoplastic lesions displaying methylation/hemimethylation at $\geq 25 \%$ of $\mathrm{CPG}$ sites (from the 12 analyzed) were considered as methylated lesions.

\section{Individual Identification by In/del Profiling}

In 4 individuals from 3 families (families 2, 4, and 6), for whom $>1$ lesion was analyzed per patient, a 32 insertion/deletion patterning was performed to confirm the common origin of the samples. All markers were typed in a single multiplex PCR, using a short amplicon strategy $(<160 \mathrm{bp})$ to improve the amplification of degraded samples. Moreover, these markers present high genetic diversi-

Table 2. Second-Hit Molecular Mechanisms in 28 Neoplastic Lesions

\begin{tabular}{lccc}
\hline Second-hit mechanism & Total lesions $(n=28)$ & Primary tumors $(n=16)$ & Metastases $(n=12)$ \\
\hline Methylation alone & $9(32.1 \%)$ & $8(50.0 \%)$ & $1(8.3 \%)$ \\
LOH alone & $7(25 \%)$ & $2(12.5 \%)$ & $5(41.7 \%)$ \\
Methylation + LOH & $5(17.9 \%)$ & $3(18.8 \%)$ & $2(16.7)$ \\
No alterations & $7(25 \%)$ & $3(18.8 \%)$ & $4(33.3 \%)$ \\
\hline
\end{tabular}


Table 3. Description of 2nd-Hit Mechanisms in CDH1 and CDH1 Hypermethylation Pattern in Neoplastic Lesions From HDGC Patients

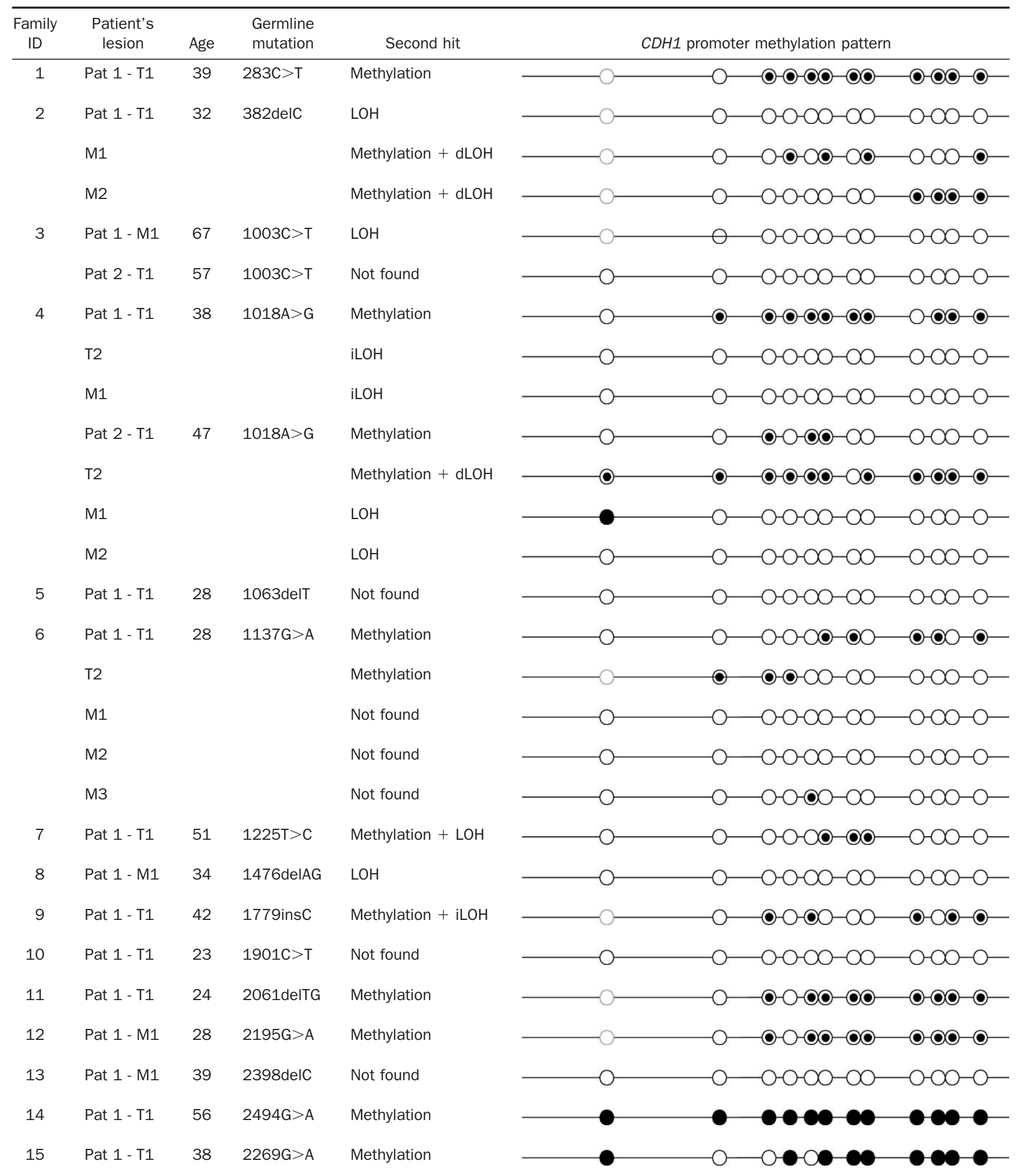

$\mathrm{LOH}$, loss of heterozygosity at informative proximal and distal flanking markers and $\mathrm{CDH} 1$ intragenic markers, when informative or LOH at informative $\mathrm{CDH} 1$ intragenic markers and proximal and distal flanking markers, when informative; dLOH, LOH only at the most distal marker (D16S3067); iLOH, LOH only at intragenic markers with no loss or no information at flanking markers. o, unmethylated CpG site; $\bullet$, Completely methylated CpG site; $\odot$, partially methylated CpG site; $\mathbf{o}$, not determined. 

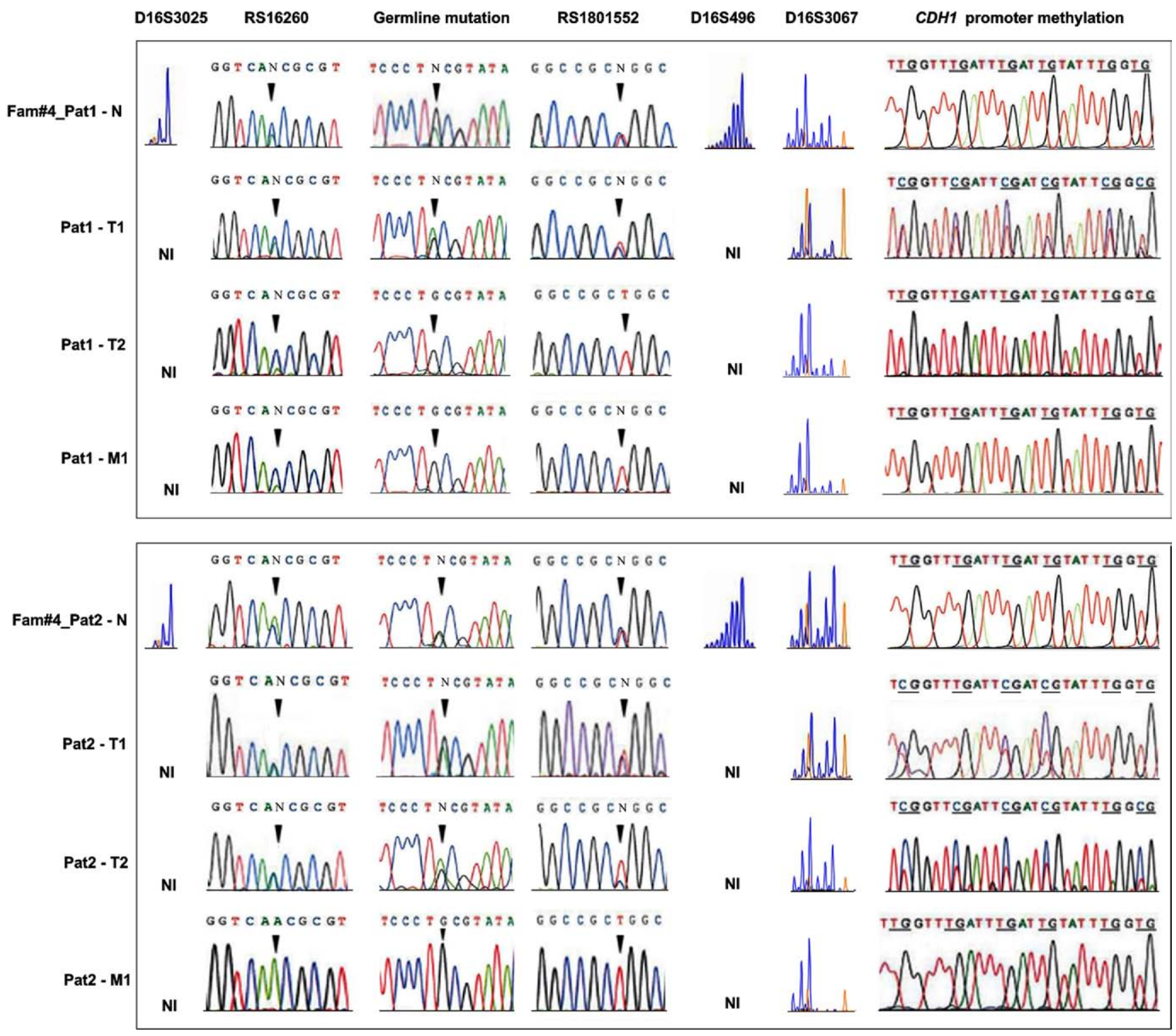

Figure 1. Examples of 2nd-hit inactivating mechanisms in HDGC tumors from 2 family members from family 4. LOH analysis using $\mathrm{CDH} 1$ flanking markers, intragenic markers, and the mutation site, and $\mathrm{CDH1}$ promoter hypermethylation analysis are depicted for every case. Variation sites, in sequencing schemes, are marked with arrowheads; CpG sites at the CDH1 promoter are underlined in the sequencing scheme. Whenever a LOH marker was not informative, NI, replaced the LOH pick. N, normal; T, primary tumor; M, metastases.

ties in major population groups and high capacity for individual discrimination ( 1 in $>100$ billions), thus providing unique genetic profiles (LG and RP, unpublished data).

\section{E-Cadherin Immunohistochemistry}

Consecutive sections from paraffin embedded tissue were used for DNA extraction and immunohistochemistry (IHC), to determine consistency or inconsistency of 2nd-hit mechanisms and E-cadherin IHC status. Human E-cadherin monoclonal antibody 4A2C7 (Zymed, Invitrogen) was used for IHC expression analysis of 3- to $5-\mu \mathrm{m}$ slides, according to manufacturer instructions. Stained sections were analyzed by an experienced pathologist (FC) and the percentage of E-cadherin positive neoplastic cells as well as the pattern of E-cadherin expression were ascertained.

\section{Statistical Analysis}

The statistical analysis was performed using the $\chi^{2}$ test. Differences were taken to be significant when $P<.05$.

\section{Results}

\section{Description of the Series of Patients and Neoplastic Lesions}

We selected for this study 17 patients belonging to 15 HDGC families carrying distinct $C D H 1$ germline mutations and meeting the International Gastric Cancer Linkage 


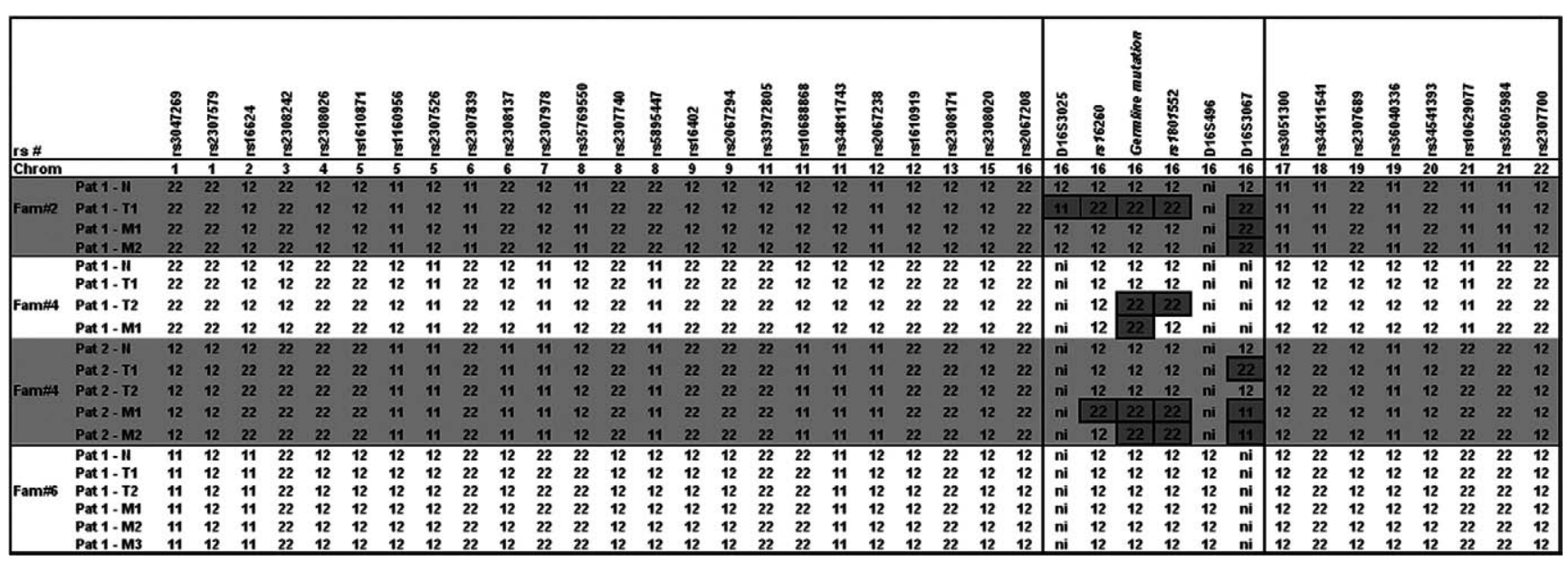

Figure 2. Genetic profiling of 4 individuals from 3 families for which multiple samples were analyzed. Analysis of 32 in/del markers in 20 chromosomes, 3 dinucleotide LOH markers flanking $\mathrm{CDH} 1$ and $\mathrm{CDH} 1$ intragenic markers. Chromosome 16 markers are flanked by 2 vertical black lines; markers displaying $\mathrm{LOH}$ are inside darker squares.

Consortium criteria (Table 1). The mean age of the patients was $39.5 \pm 12.6$ years (range, 23-67). We independently analyzed a total of 28 neoplastic lesions, collected from 17 patients for $\mathrm{CDH} 1$ promoter hypermethylation, $\mathrm{LOH}$, and mutations within the hotspot exons $7-10$, where CDH1 somatic mutations cluster. ${ }^{26}$ We did not extend the mutation analyses to all $C D H 1$ exons owing to a lack of material. To dilute contamination with DNA from normal cells, DNA was extracted from macrodissected areas enriched in neoplastic cells. This approach allowed us to specifically analyze molecular alterations occurring in neoplastic cells that are easily masked when a large population of normal cells contaminates tumor samples.

\section{Frequency of 2nd-Hit Inactivation Mechanisms in HDGC Families and Neoplastic Lesions}

We found somatic epi/genetic alterations in $\geq 1$ neoplastic lesions from $80.0 \%$ of the families analyzed (12/15 probands).

These somatic epi/genetic alterations were present in $75 \%$ of the neoplastic lesions analyzed (21/28 lesions): $81.3 \%$ in primary carcinomas $(13 / 16)$ and $66.7 \%$ in metastases (8/12) (Tables 2 and 3$)$. In 3 primary tumors and 4 metastases, no 2 nd-hit mechanism was identified. All alterations found in HDGC neoplastic lesions were absent from constitutional DNA, representing the 2nd-hit inactivation mechanism.

\section{Epigenetic and Genetic CDH1 Alterations Occur Either Alone or Simultaneously in HDGC Neoplastic Lesions}

From the 28 HDGC lesion analyzed, $\mathrm{CDH} 1$ promoter hypermethylation was found in 9 (32.1\%) cases, $\mathrm{LOH}$ in $7(25.0 \%)$, and both alterations in 5 cases $(17.9 \%)$, most probably reflecting tumor population heterogeneity. Examples of a 2nd-hit profile in HDGC neoplastic lesions are depicted in Figure 1. We did not find somatic mutations, in the regions analyzed, in any of the neoplastic lesions.

In HDGC primary tumors $(n=16)$, we found $C D H 1$ promoter hypermethylation in $8(50 \%)$ cases, $\mathrm{LOH}$ in 2 $(12.5 \%)$, and both alterations in 3 (18.8\%; Table 1; Figure 1). $C D H 1$ epigenetic alterations alone were present in $50 \%$ of the cases, whereas $\mathrm{LOH}$, concomitantly or not with epigenetic alterations, was present in $31.3 \%$ of the cases (Table 2; Figure 1). The 8 neoplastic lesions harboring CDH1 promoter hypermethylation only, retained both alleles and did not show somatic mutations.

In metastatic lesions $(n=12)$ we found $C D H 1$ promoter hypermethylation in $1(8.3 \%)$ case, $\mathrm{LOH}$ in 5 (41.7\%), and both alterations in $2(16.7 \%)$. In metastases, $8.3 \%$ of the lesions displayed $\mathrm{CDH} 1$ epigenetic alterations only, whereas $58.3 \%$ displayed LOH concomitantly or not with $C D H 1$ hypermethylation (Table 2).

The comparison of 2nd-hit mechanisms in primary tumors and metastatic lesions showed that primary tumors displayed preferentially epigenetic alterations (50\%) as single events, whereas metastatic lesions displayed preferentially genetic $(\mathrm{LOH})$ concomitantly or not with epigenetic alterations $(58.3 \% ; P=.0274$; Table 2).

The tumor-associated methylation observed in our series of HDGC patients is very unlikely age related because the majority of patients were $<50$ years old at diagnosis (Tables 1 and 3). Sixty-nine percent of patients $<50$ years old (9/13) displayed $C D H 1$ promoter hypermethylation in their tumors whereas $50 \%(2 / 4)$ of patients $>50$ years old had hypermethylation in their tumors.

\section{Different Lesions From the Same Patient Display Distinct Patterns of 2nd-Hit Mechanisms}

In 3 families (families 2, 4, and 6), multiple lesions from the same patient were analyzed. In family 2 , we 
analyzed 1 primary tumor foci and 2 metastases and found that, although the primary tumor displayed $\mathrm{LOH}$, both metastases displayed methylation concomitant with distal LOH (Table 3). Moreover, the LOH pattern displayed by the primary tumor foci showed loss of the complete $C D H 1$ coding region while in both metastases only the distal 3' LOH marker (D16S3067) showed loss (Figure 2).

In family 4, we studied 2 patients: 2 primary tumor foci and 1 metastasis from patient 1 and, 2 primary tumor foci and 2 metastases from patient 2. Primary tumors from patient 1 displayed different 2 nd-hit mechanisms; 1 displayed methylation and the other $\mathrm{LOH}$ at $\geq 2$ intragenic markers (germline mutation and rs1801552). The metastasis displayed $\mathrm{LOH}$ at a single intragenic marker (germline mutation; Table 3 and Figure 1). As for patient 2, primary tumor foci displayed also different 2nd-hit mechanisms; 1 displayed methylation only and the other displayed methylation concomitantly with distal LOH (D16S3067). The 2 metastases from patient 2 displayed $\mathrm{LOH}$ only, but with different patterns of loss (Table 3 and Figure 1).

The results in these 2 families likely indicate that the different lesions analyzed in each patient's stomach/metastases arose as a result of independent 2 nd-hit mechanisms, acting somatically at the CDH1 locus.

In family 6, several lesions were analyzed from a single patient and a different scenario was observed: The 2 primary tumor foci analyzed showed methylation only, but in the 3 ovarian metastasis no methylation, LOH, or somatic mutation in any of the $16 \mathrm{CDH} 1$ exons (exceptionally in this case, enough DNA was available for CDH1 complete mutation screening) was found as a 2 nd-hit mechanism (Table 3).

We validated all 2 nd-hit results by confirming the common origin of all neoplastic lesions and matched normal tissue, from each patient, with a large set of insertion/deletion markers in 20 different chromosomes. This analysis allowed us to infer whether each lesion arose independently in each patient's stomach/metastases or whether all lesions were likely to arise as a result of a common trigger mechanism. Moreover, we used the insertion/deletion patterning to exclude allele dropout as a potential reason for loss at single $\mathrm{CDH} 1 \mathrm{LOH}$ markers. LOH was commonly observed in HDGC tumors at the CDH1 locus while no allele dropout occurred in the PCR amplification of the 32 insertion/deletion markers.

\section{The E-Cadherin Immunoexpression in HDGC Tumors Is Generally Consistent With the Combination of Germline and/or Somatic Defects}

We performed E-cadherin IHC in 26 of 28 lesions using an antibody that recognizes the cytoplasmic domain of the protein and therefore is expected to stain E-cadherin full-length or near full-length proteins only. We assessed the percentage of positive and negative cells for E-cadherin immunoreactivity as well as the cellular localization of the protein (Table 4). For all cases, we had as internal control normal E-cadherin expression either at the foveolar zone or in nondisrupted glands, adjacent to all tumor areas. All lesions analyzed contained neoplastic cells displaying abnormal or absent E-cadherin protein expression and localization, with the exception of neoplastic cells belonging to tumor from family 12, which displayed only homogeneous membrane expression. In most cases we observed consistency of IHC results and the combination of germline and somatic defects (Table 4). All these results as well as their interpretation are provided in Table 4.

Both the percentage of expressing cells and the cellular localization of the protein were independent of type and site of $\mathrm{CDH} 1$ germline mutation as well as from type of CDH1 somatic inactivation mechanism and type of lesion analyzed (primary tumor or metastasis).

\section{The Type of 2nd-Hit Mechanism Is Not Dependent on the Type and Site of $\mathrm{CDH} 1$ Germline Mutation}

We performed association studies in an effort to understand whether the type of 2nd-hit in HDGC tumors was dependent on the $\mathrm{CDH} 1$ germline mutation type. We analyzed whether individuals carrying either truncating or missense mutations displayed any specific type of 2nd-hit inactivation mechanism and verified that no association exists between these 2 parameters.

In addition, no association was found between the site of $C D H 1$ germline mutation and the type of $C D H 1$ somatic inactivation mechanism. Somatic promoter hypermethylation alone and $\mathrm{LOH}$ alone or with concurrent promoter hypermethylation occurred in tumors from carriers harboring germline mutations dispersed throughout the $\mathrm{CDH1}$ gene (Figure 3).

\section{Discussion}

Individuals carrying germline mutations in cancer-related genes are at increased risk of developing neoplasia during their lifetime. Overall, carriers of $C D H 1$ germline mutations have a $>70 \%$ lifetime risk (penetrance) of developing diffuse gastric cancer; female mutation carriers have an additional risk of $40 \%$ of developing breast cancer. $^{27}$

Asymptomatic CDH1 mutation carriers are offered the opportunity to undergo total prophylactic gastrectomy, therefore preventing the disease to develop in the target organ. However, this is a dramatic decision for apparently healthy carriers of $C D H 1$ germline mutations; if prophylactic gastrectomy is not performed, the overall outcome of HDGC patients is expected to remain poor. Most HDGC patients carrying a $C D H 1$ mutation develop preclinical, not detectable by endoscopy, multifocal tumors with an increased ability for metastatic spread. ${ }^{15}$ When these patients present to the clinics, commonly the dis- 
Table 4. Interpretation of E-Cadherin Immuno-Expression in HDGC Neoplastic Lesions and Its Relationship With Germline and Somatic $C D H 1$ Defects

\begin{tabular}{|c|c|c|c|c|c|c|c|c|}
\hline $\begin{array}{l}\text { Family } \\
\text { ID }\end{array}$ & $\begin{array}{l}\text { Patient's } \\
\text { lesion }\end{array}$ & $\begin{array}{l}\text { Germline } \\
\text { mutation }\end{array}$ & $\begin{array}{l}\text { Mutation } \\
\text { type }\end{array}$ & Second hit & $\begin{array}{l}\text { E-cadherin-positive } \\
\text { cells ( } \% \text { and } \\
\text { pattern) }\end{array}$ & Comment & $\begin{array}{l}\text { E-cadherin- } \\
\text { negative } \\
\text { cells (\%) }\end{array}$ & Comment \\
\hline 1 & Pat 1 - T1 & $283 C>T$ & Truncating & Meth & 0 & - & 100 & $\begin{array}{l}\text { Consistent with methylation } \\
\text { of WT allele and no } \\
\text { protein derived from } \\
\text { germline mutant allele }\end{array}$ \\
\hline \multirow[t]{3}{*}{2} & Pat 1 - T1 & 382delC & Truncating & $\mathrm{LOH}$ & 0 & - & 100 & $\begin{array}{l}\text { Consistent with } \mathrm{LOH} \text { of WT } \\
\text { allele and no protein } \\
\text { derived from germline } \\
\text { mutant allele }\end{array}$ \\
\hline & Pat 1 - M1 & & & Meth + dLOH & $\begin{array}{l}50 \text { (hetero memb } \\
\text { or dotted cyto) }\end{array}$ & $\begin{array}{l}\text { Consistent with dLOH } \\
\text { leading to aberrant } \\
\text { expression (?) and no } \\
\text { protein derived from } \\
\text { germline mutant allele }\end{array}$ & 50 & $\begin{array}{l}\text { Consistent with methylation } \\
\text { of WT allele and no } \\
\text { protein derived from } \\
\text { germline mutant allele. }\end{array}$ \\
\hline & Pat $1-\mathrm{M} 2$ & & & Meth + dLOH & $\begin{array}{l}\text { 50-75 (dotted } \\
\quad \text { cyto) }\end{array}$ & $\begin{array}{l}\text { Consistent with dLOH } \\
\text { leading to aberrant } \\
\text { expression (?) and no } \\
\text { protein derived from } \\
\text { germline mutant allele }\end{array}$ & $25-50$ & $\begin{array}{l}\text { Consistent with methylation } \\
\text { of WT allele and no } \\
\text { protein derived from } \\
\text { germline mutant allele }\end{array}$ \\
\hline \multirow[t]{2}{*}{3} & Pat 1 - M1 & $1003 C>T$ & Truncating & $\mathrm{LOH}$ & 0 & - & 100 & $\begin{array}{l}\text { Consistent with LOH of WT } \\
\text { allele and no protein } \\
\text { derived from germline } \\
\text { mutant allele }\end{array}$ \\
\hline & Pat 2 - T1 & & & Not found & 75 (dotted cyto) & & 25 & \\
\hline \multirow[t]{7}{*}{4} & Pat 1 - T1 & $1018 A>G$ & Missense & Meth & 0 & - & 100 & $\begin{array}{l}\text { Consistent with biallelic } \\
\text { methylation }\end{array}$ \\
\hline & Pat 1 - T2 & & & iLOH & Not done & Not analyzed & Not done & Not analyzed \\
\hline & Pat 1 - M1 & & & iLOH & 100 (memb) & $\begin{array}{l}\text { Consistent with LOH of WT } \\
\text { allele and membrane } \\
\text { expression of the } \\
\text { germline mutant allele* }\end{array}$ & 0 & - \\
\hline & Pat $2-\mathrm{T} 1$ & $1018 A>G$ & & Meth & 0 & - & 100 & $\begin{array}{l}\text { Consistent with biallelic } \\
\text { methylation }\end{array}$ \\
\hline & Pat 2 - T2 & & & Meth + dLOH & $\begin{array}{l}50 \text { (homo and } \\
\text { hetero memb) }\end{array}$ & $\begin{array}{l}\text { Consistent with expression } \\
\text { germline mutant allele or } \\
\text { with dLOH leading to } \\
\text { aberrant expression (?) }\end{array}$ & 50 & $\begin{array}{l}\text { Consistent with biallelic } \\
\text { methylation }\end{array}$ \\
\hline & Pat 2 - M1 & & & $\mathrm{LOH}$ & $\begin{array}{l}\text { 25-50 (hetero } \\
\text { memb) }\end{array}$ & $\begin{array}{l}\text { Consistent with LOH of WT } \\
\text { allele and membrane } \\
\text { expression of the } \\
\text { germline mutant allele* }\end{array}$ & $50-75$ & Inconsistent \\
\hline & Pat $2-\mathrm{M} 2$ & & & $\mathrm{LOH}$ & 0 & Inconsistence & 100 & Inconsistence \\
\hline 5 & Pat 1 - T1 & 1063delT & Truncating & Not found & $\begin{array}{l}<25 \text { (hetero } \\
\text { memb) }\end{array}$ & & $>75$ & \\
\hline \multirow[t]{5}{*}{6} & Pat 1 - T1 & $1137 G>A$ & Truncating & Meth & $\begin{array}{l}\text { 25-50 (hetero } \\
\text { memb; dotted } \\
\text { cyto) }\end{array}$ & $\begin{array}{l}\text { Consistent with methylation } \\
\text { of WT allele and aberrant } \\
\text { protein derived from } \\
\text { germline mutant allele }\end{array}$ & $50-75$ & $\begin{array}{l}\text { Consistent with biallelic } \\
\text { methylation }\end{array}$ \\
\hline & Pat 1 - T2 & & & Meth & $\begin{array}{l}\text { 25-50 (hetero } \\
\text { memb; dotted } \\
\text { cyto) }\end{array}$ & $\begin{array}{l}\text { Consistent with methylation } \\
\text { of WT allele and aberrant } \\
\text { protein derived from } \\
\text { germline mutant allele }\end{array}$ & $50-75$ & $\begin{array}{l}\text { Consistent with biallelic } \\
\text { methylation }\end{array}$ \\
\hline & Pat $1-\mathrm{M} 1$ & & & Not found & $<25$ (hetero cyto) & & $>75$ & \\
\hline & Pat $1-\mathrm{M} 2$ & & & Not found & $<25$ (dotted cyto) & & $>75$ & \\
\hline & Pat $1-\mathrm{M} 3$ & & & Not found & $<25$ (dotted cyto) & & $>75$ & \\
\hline 7 & Pat 1 - T1 & $1225 \mathrm{~T}>\mathrm{C}^{42}$ & Missense & Meth + LOH & $\begin{array}{l}25-50 \text { (hetero } \\
\text { memb or dotted } \\
\text { cyto) }\end{array}$ & $\begin{array}{l}\text { Consistent with methylation } \\
\text { of WT allele and aberrant } \\
\text { protein derived from } \\
\text { germline mutant allele }{ }^{42}\end{array}$ & $50-75$ & $\begin{array}{l}\text { Consistent with biallelic } \\
\text { methylation (?) }\end{array}$ \\
\hline 8 & Pat 1 - M1 & 1476delAG & Truncating & $\mathrm{LOH}$ & $\begin{array}{l}\text { 25-50 (hetero } \\
\text { memb) }\end{array}$ & Inconsistence* & $50-75$ & $\begin{array}{l}\text { Consistent with methylation } \\
\text { of WT allele and no } \\
\text { protein derived from } \\
\text { germline mutant allele. }\end{array}$ \\
\hline 9 & Pat 1 - T1 & 1779insC & Truncating & Meth + iLOH & $\begin{array}{c}<25 \text { (hetero memb } \\
\text { or dotted cyto) }\end{array}$ & Inconsistence* & $>75$ & $\begin{array}{l}\text { Consistent with } \mathrm{LOH} \text { or } \\
\text { methylation of WT allele } \\
\text { and no protein derived } \\
\text { from germline mutant } \\
\text { allele }\end{array}$ \\
\hline 10 & Pat 1 - T1 & $1901 C>T$ & $\begin{array}{l}\text { Truncating/ } \\
\text { missense }\end{array}$ & Not found & 0 & & 100 & \\
\hline 11 & Pat $1-\mathrm{T} 1$ & 2061delTG & Truncating & Meth & 0 & - & 100 & $\begin{array}{l}\text { Consistent with methylation } \\
\text { of WT allele and no } \\
\text { protein derived from } \\
\text { germline mutant allele }\end{array}$ \\
\hline
\end{tabular}


Table 4. (Continued)

\begin{tabular}{|c|c|c|c|c|c|c|c|c|}
\hline $\begin{array}{l}\text { Family } \\
\text { ID }\end{array}$ & $\begin{array}{l}\text { Patient's } \\
\text { lesion }\end{array}$ & $\begin{array}{l}\text { Germline } \\
\text { mutation }\end{array}$ & $\begin{array}{l}\text { Mutation } \\
\text { type }\end{array}$ & Second hit & $\begin{array}{l}\text { E-cadherin-positive } \\
\text { cells ( } \% \text { and } \\
\text { pattern) }\end{array}$ & Comment & $\begin{array}{l}\text { E-cadherin- } \\
\text { negative } \\
\text { cells }(\%)\end{array}$ & Comment \\
\hline 12 & Pat 1 - M1 & $2195 G>A^{42}$ & $\begin{array}{l}\text { Truncating/ } \\
\text { missense }\end{array}$ & Meth & 100 (memb) & $\begin{array}{l}\text { Consistent with methylation } \\
\text { of WT allele and } \\
\text { membrane expression of } \\
\text { the germline mutant } \\
\text { allele (missense) }{ }^{42}\end{array}$ & 0 & $\begin{array}{l}\text { Consistent with biallelic } \\
\text { methylation }\end{array}$ \\
\hline 13 & Pat 1 - M1 & 2398delC & Truncating & Not found & Not done & & Not done & \\
\hline 14 & Pat 1- T1 & $2494 G>A$ & Missense & Meth & $<25$ (dotted cyto) & $\begin{array}{l}\text { Consistent with methylation } \\
\text { of WT allele and aberrant } \\
\text { expression of the } \\
\text { germline mutant allele }\end{array}$ & $>75$ & $\begin{array}{l}\text { Consistent with biallelic } \\
\text { methylation }\end{array}$ \\
\hline 15 & Pat 1 - T1 & $2269 G>A$ & Missense & Meth & 25 (memb) & $\begin{array}{l}\text { Consistent with methylation } \\
\text { of WT allele and } \\
\text { membrane expression of } \\
\text { the germline mutant } \\
\text { allele } 41\end{array}$ & 75 & $\begin{array}{l}\text { Consistent with methylation } \\
\text { of WT allele and lack of } \\
\text { membrane expression of } \\
\text { the germline mutant } \\
\text { allele }{ }^{41}\end{array}$ \\
\hline
\end{tabular}

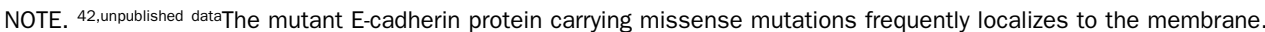

Meth, methylation; memb, membrane; cyto, cytoplasm; hetero, heterogeneous; homo, homogeneous; WT, wild type.

* No protein is expected to be produced from the germline mutant allele and if leakage occur, the truncated peptide generated by the germline mutation does not encompass a transmembrane nor a cytoplasmic domain of E-cadherin domain hampering antibody binding; ${ }^{41}$ The 2269 mutation generates a protein that may or may not localize to the membrane.

ease is advanced and spread, and they only receive palliative treatments. This illustrates the reason why prophylactic gastrectomy is recommended before clinical disease presentation, that is, before the third decade of life, ${ }^{28}$ and why efforts should be made to determine specific molecular mechanisms, occurring in these tumors, that may constitute potential targets for therapy.

Current knowledge shows that HDGC tumors initiate when the remaining $C D H 1$ wild-type allele becomes inactive in mutation carrier's stomachs, mainly through promoter hypermethylation, ${ }^{10-12,14}$ according to Knudson's "2nd-hit" hypothesis. ${ }^{9}$ Therefore, HDGC patients displaying $\mathrm{CDH} 1$ promoter hypermethylation, as a 2 ndhit, in their neoplastic lesions, would benefit from the administration of drugs leading to the reversion of $C D H 1$ promoter methylated state. HDAC inhibitors and DNAdemethylating agents emerge, in this view, as attractive drugs to use in combination with classical chemotherapy agents. The use of such a strategy implies the definitive proof that hypermethylation is the most common mechanism of CDH1 wild-type allele inactivation in HDGC neoplastic lesions, and the unique mechanism in different neoplastic lesions from the same patient. This knowledge is critical for the therapeutic management of HDGC patients.

The present report encloses the largest series of neoplastic lesions from patients belonging to $C D H 1$ germline mutation positive HDGC families, ever analyzed for CDH1 2nd-hit inactivating mechanisms (Table 1). Moreover, in this work we systematically analyzed all lesions for $C D H 1$ promoter hypermethylation using CpG methylation-independent PCR and sequencing, $\mathrm{LOH}$ with intragenic and flanking markers of the CDH1 locus, and somatic mutations at $\mathrm{CDH} 1$ hotspot regions, using multiplex PCR having the germline mutation as an internal control. Moreover, we used a large genome covering insertion/deletion patterning to confirm the common origin of different neoplastic lesions and matched normal samples from each individual as well as to exclude allele dropout in the $\mathrm{LOH}$ analysis. This approach was never used in previous studies of CDH1 2nd-hit analysis, in HDGC patients, precluding a trustworthy comparison of results. Nevertheless, by combining our results with those previously published in this disease, ${ }^{10-12,14}$ CDH1 2 nd-hit inactivation mechanisms are currently identified in $\geq 1$

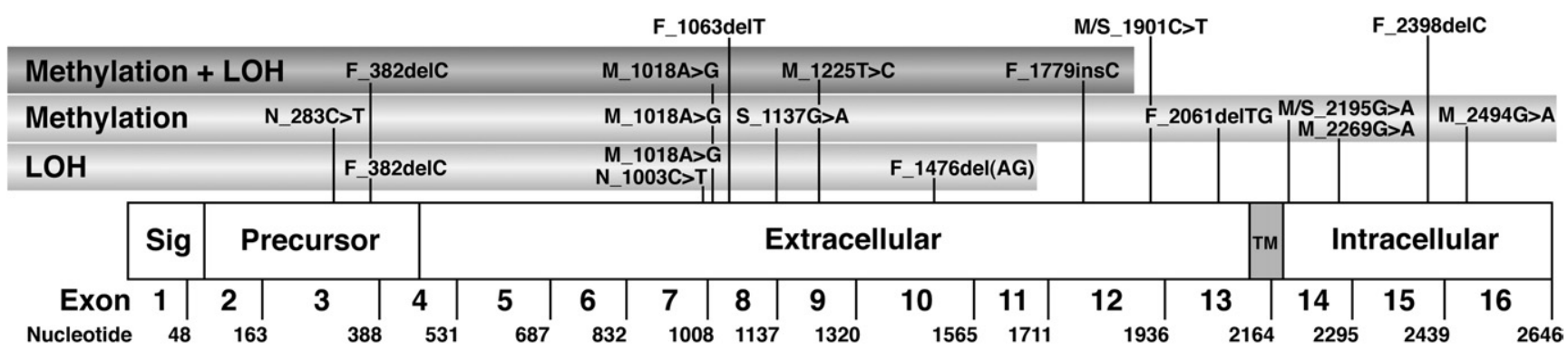

Figure 3. Schematic representation of 2nd-hit inactivating mechanisms superimposed with germline mutations type and site. $C D H 1$ germline mutations are preceded by letters indicating the type of mutation $\mathrm{N}$ (nonsense), $\mathrm{F}$ (frameshift), $\mathrm{M}$ (missense), and M/S (missense/splicing), and are aligned according to the 2 nd-hit inactivating mechanism. 
tumor from $34.1 \%(n=28)$ of the HDGC families reported to date $(n=82)$.

Seventy-five percent of HDGC neoplastic lesions, herein analyzed, displayed somatic $C D H 1$ epi/genetic inactivation. This result is higher than that previously obtained combining all HDGC tumors analyzed (29.6\%), ${ }^{10-12,14}$ and similar to that described for sporadic gastric tumors with diffuse components (90\%). ${ }^{13}$ Reasons for this discrepancy are likely related to the methodologic approach used, as well as with the lack of information on $\mathrm{CDH} 1 \mathrm{LOH}$ analysis in previous reports. In other cancer-associated syndromes, the frequency of 2 nd-hit mechanisms identified is similar to that herein described as $60 \%$ of hereditary nonpolyposis colorectal cancer tumors displaying $b M L H 1$ hypermethylation and $\mathrm{LOH},{ }^{17,18} 75 \%$ of familial ovarian cancer displaying BRCA2 LOH, ${ }^{19}$ and $83 \%$ of familial adenomatous polyposis desmoid tumors displaying APC somatic mutations and deletions. ${ }^{20}$

To have a full picture of how CDH1 are inactivated in this invasive and spreading disease, we have analyzed a series of primary tumors and metastasis as well as several primary tumor foci and metastatic lesions from the same patient, whenever possible. This analysis allowed us to verify that (1) the majority of primary tumors displayed epigenetic alterations, (2) the majority of metastatic lesions displayed $\mathrm{LOH},(3)$ neoplastic lesions, primary or metastatic, frequently display $>1 C D H 1$ 2nd-hit inactivating mechanism, and (4) different lesions from the same patient display distinct $C D H 12$ 2nd-hit inactivating mechanisms.

The initial observation of $\mathrm{CDH} 1$ promoter hypermethylation as the most common 2 nd-hit mechanism ${ }^{10,11,14}$ is consistent with the fact that only primary HDGC tumors have been analyzed. Our own results demonstrate the same when only primary tumors are considered $(11 / 16$; $68.8 \%$ ). Nevertheless, when the analysis is extended to multiple foci from the same patient and/or to metastatic lesions, this scenario is completely changed and CDH1 hypermethylation becomes 1 among other 2nd-hit mechanisms in each patient, at the same time that $\mathrm{LOH}$ emerges as the most prevalent mechanism in metastases.

The biological reasons underlying our results are probably related to the nature of HDGC itself. One to $>100$ small foci of signet-ring cell gastric carcinoma are found in the stomachs of asymptomatic mutation carriers. ${ }^{15,16}$ These lesions evolve and give rise to invasive cancer that populates the whole stomach as well as peripheral and distant lymph nodes. ${ }^{15}$ In light of our present results, each of these foci is likely to arise from independent, 2nd-hit-inactivating mechanisms affecting the CDH1 gene. Moreover, it is also plausible to believe that the vicinity of different initial foci, originated from distinct 2nd-hit mechanisms, cluster together creating a mixed population of neoplastic cells, heterogeneous at the molecular level, that ultimately constitute the bulk of the tumor. Neoplastic cells from these mixed populations are those probably traveling to distant sites and giving rise to metastases carrying distinct or even concomitant 2nd-hit mechanisms. Because our analysis was performed in advanced tumors, most probably the finding of $>1 \mathrm{CDH} 1$ 2nd-hit-inactivating mechanism in the same lesion reflects the initial intratumor heterogeneity. Although rare, more than one 2nd hit has been described in tumors from other hereditary, cancer-related syndromes. ${ }^{17,18}$

The observations herein reported are consistent with those that we previously described in colorectal cancers: Primary tumors harbor either BRAF or KRAS, and corresponding lymph node metastases accumulate mutations in both genes. ${ }^{29}$ These results demonstrate that somatic alterations either occur during progression to metastasis, in some cases, or and in accordance with Bernards and Weinberg, ${ }^{30}$ that important components of the genotype of metastasis are already implanted early in tumorigenesis, in small primary tumor cells populations that have a greater ability to dispatch metastatic pioneers to distant sites in the body.

The most important consequence of our observations in HDGC neoplastic lesions is related to the clinical intervention and therapeutic approach to be used in a disease that remains without treatment. The design of any therapeutic approach, at this point, needs to take into account the targeting of different and independently arising populations of neoplastic cells. An approach based on epigenetic drugs only will fail because of the expected insensitivity of cells harboring $\mathrm{CDH} 1$ somatic mutations or LOH. This hypothesis of insensitivity to a specific drug by a subpopulation of tumor cells, although in a different context, is elegantly illustrated by the results obtained by Taniguchi et al, ${ }^{31}$ who described that patients with non-small-cell lung cancer constituted by 2 subpopulations of tumors cells displaying different molecular features (mutated and nonmutated for epidermal growth factor receptor [EGFR]) did not respond well to gefitinib. Moreover, the overall survival of these nonsmall-cell lung cancer patients after gefitinib treatment was significantly reduced compared with patients with EGFR-mutant tumor cells only, demonstrating the lack of benefit after this intervention.

The use of HDAC inhibitors and DNA-demethylating agents would likely be useful in the setting of patients where malignancy remains preclinical, a setting where at least half of the tumor foci may be already hypermethylated. Nevertheless, for those patients who present with tumors displaying both epigenetic and genetic alterations, new therapeutic strategies need to be developed.

Our group has showed that cells transduced with mutant forms of E-cadherin harboring mutations in the extracellular domain or displaying complete loss of $\mathrm{CDH} 1$ expression modify the stability of E-cadherin/EGFR heterodimer, enhancing cancer cell motility through the activation of an EGFR downstream target. This effect was shown to be reverted upon EGFR pharmacologic inhibi- 
tion and cells lacking functional E-cadherin stopped moving. ${ }^{32}$ Moreover, E-cadherin negative ovarian cancer cells have been recently shown to overexpress $\alpha$-5-integrin induced by activation of the EGFR pathway. ${ }^{33}$ The use of $\alpha 5$ - $\beta 1$-integrin-blocking antibody in mice xenografted with an ovarian cancer cell line, overexpressing $\alpha 5$-integrin, induced by E-cadherin down-regulation, significantly reduced the number of metastases and increased survival of the mice. In this same study, patients with high levels of $\alpha 5$-integrin died 9 months earlier than those displaying low $\alpha 5$-integrin expression. ${ }^{33}$ Following a similar rational, Kawajiri et $\mathrm{al}^{34}$ recently showed that the transforming growth factor- $\beta$ - $\mathrm{R}$ inhibitor, A-77, decreased the adhesive and invasive abilities of diffuse gastric cancer cells to the mice peritoneum, as well as the size and number of metastatic nodes, and demonstrated that this effect was mediated by decreased expression of integrins.

All these studies describe drugs that reduce tumor cell migration and metastasis potentially increasing patient survival, that specifically act in cells lacking E-cadherin expression. Such drugs are expected to target cells displaying genetic $C D H 1$ alterations in the same way that demethylating agents and HDAC inhibitors are expected to re-induce E-cadherin expression in cells displaying CDH1 promoter hypermethylation. The concurrent use of these 2 types of approaches may be applicable to HDGC patients with tumors displaying epigenetic and genetic alterations. When used early, epigenetic drugs would be expected to restore $C D H 1$ expression in small foci of primary tumor, eventually arresting them in an epithelial state. Genetic alterations, as $\mathrm{LOH}$, which seem to be acquired later in HDGC progression, could be then targeted with drugs such as EGFR and $\alpha 5$ - $\beta 1$-integrinblocking antibodies or transforming growth factor- $\beta$-R small synthetic molecules to prevent cells from migrating and metastasis from establishing. ${ }^{35-40}$

In conclusion, our data support the previously published rate of $\mathrm{CDH} 1$ promoter hypermethylation as a 2nd-hit in HDGC primary tumors, and adds $\mathrm{LOH}$ as a key mechanism, mainly in metastatic lesions. Because of the concomitance and heterogeneity of these alterations in neoplastic lesions and the plasticity of hypermethylated promoters during tumor initiation and progression, drugs targeting only epigenetic alterations might not be effective, particularly in patients with metastatic HDGC.

\section{References}

1. Khushalani N. Cancer of the esophagus and stomach. Mayo Clin Proc 2008;83:712-722.

2. Bosetti C, Bertuccio $P$, Levi $F$, et al. Cancer mortality in the European Union, 1970-2003, with a joinpoint analysis. Ann Oncol 2008;19:631-640.

3. Berx G, Becker KF, Höfler $\mathrm{H}$, et al. Mutations of the human E-cadherin (CDH1) gene. Hum Mutat 1998;12:226-237.

4. Machado JC, Soares P, Carneiro F, et al. E-cadherin gene mutations provide a genetic basis for the phenotypic divergence of mixed gastric carcinomas. Lab Invest 1999;79:459-465.
5. Guilford P, Hopkins J, Harraway J, et al. E-cadherin germline mutations in familial gastric cancer. Nature 1998;392:402-405.

6. Oliveira C, Bordin MC, Grehan N, et al. Screening of E-Cadherin in gastric cancer families reveals germ-line mutations only in hereditary diffuse gastric cancer kindred. Hum Mutat 2002;19:510517.

7. Carneiro F, Oliveira C, Suriano G, et al. Molecular pathology of familial gastric cancer, with an emphasis on hereditary diffuse gastric cancer. J Clin Pathol 2008;61:25-30.

8. Suriano G, Seixas S, Rocha J, et al. A model to infer the pathogenic significance of $\mathrm{CDH} 1$ germline missense variants. J Mol Med 2006;84:1023-1031.

9. Knudson AG Jr. Mutation and cancer: statistical study of retinoblastoma. Proc Natl Acad Sci U S A 1971;68:820-823.

10. Grady WM, Willis J, Guilford PJ, et al. Methylation of the CDH1 promoter as the second genetic hit in hereditary diffuse gastric cancer. Nat Genet 2000;26:16-17.

11. Corso G, Roviello F, Paredes J, et al. Characterization of the P373L E-cadherin germline missense mutation and implication for clinical management. Eur J Surg Oncol 2007;33:1061-1067.

12. Oliveira C, de Bruin J, Nabais S, et al. Intragenic deletion of $\mathrm{CDH}-1$ as the inactivating mechanism of the wild-type allele in a HDGC tumor. Oncogene 2004;23:9192-9196.

13. Machado JC, Oliveira C, Carvalho R, et al. E-cadherin gene (CDH1) promoter methylation as the second hit in sporadic diffuse gastric carcinoma. Oncogene 2001;20:1525-1528.

14. Barber M, Murrell A, Ito $Y$, et al. Mechanisms and sequelae of $\mathrm{E}$-cadherin silencing in hereditary diffuse gastric cancer. J Pathol 2008;216:295-306.

15. Carneiro F, Huntsman DG, Smyrk TC, et al. Model of the early development of diffuse gastric cancer in E-cadherin mutation carriers and its implications for patient screening. J Pathol 2004, 203:681-687.

16. Huntsman DG, Carneiro F, Lewis FR, et al. Early gastric cancer in young, asymptomatic carriers of germ-line E-cadherin mutations. N Engl J Med 2001;344:1904-1909.

17. Ollikainen M, Hannelius $U$, Lindgren $\mathrm{CM}$, et al. Mechanisms of inactivation of MLH1 in hereditary nonpolyposis colorectal carcinoma: a novel approach. Oncogene 2007;26:4541-4549.

18. Kuismanen SA, Holmberg MT, Salovaara R, et al. Genetic and epigenetic modification of MLH1 accounts for a major share of microsatellite-unstable colorectal cancers. Am J Pathol 2000; 156:1773-1779.

19. Press JZ, De Luca A, Boyd N, et al. Ovarian carcinomas with genetic and epigenetic BRCA1 loss have distinct molecular abnormalities. BMC Cancer 2008;8:17.

20. Latchford A, Volikos E, Johnson V, et al. APC mutations in FAPassociated desmoid tumors are non-random but not 'just right'. Hum Mol Genet 2007;16:78-82.

21. Humar B, Guilford P. Hereditary diffuse gastric cancer and lost cell polarity: a short path to cancer. Future Oncol 2008;4:229 239.

22. Ou JN, Torrisani J, Unterberger A, et al. Histone deacetylase inhibitor trichostatin A induces global and gene-specific DNA demethylation in human cancer cell lines. Biochem Pharmacol 2007;73:1297-1307.

23. Caldas C, Carneiro F, Lynch HT, et al. Familial gastric cancer: overview and guidelines for management. J Med Genet 1999;36: 873-880.

24. Graff JR, Herman JG, Myöhänen S, et al. Mapping patterns of CpG island methylation in normal and neoplastic cells implicates both upstream and downstream regions in de novo methylation. J Biol Chem 1997:272:22322-22329.

25. Graff JR, Gabrielson E, Fujii H, et al. Methylation patterns of the E-cadherin 5' $\mathrm{CpG}$ island are unstable and reflect the dynamic, heterogeneous loss of E-cadherin expression during metastatic progression. J Biol Chem 2000;275:2727-2732. 
26. Becker KF, Hofler H. Frequent somatic allelic inactivation of the E-cadherin gene in gastric carcinomas. J Natl Cancer Inst 1995; 87:1082-1084.

27. Pharoah PD, Guilford $P$, Caldas $C$. Incidence of gastric cancer and breast cancer in $\mathrm{CDH} 1$ (E-cadherin) mutation carriers from hereditary diffuse gastric cancer families. Gastroenterology 2001;121: 1348-1353.

28. Lynch HT, Kaurah P, Wirtzfeld D, et al. Hereditary diffuse gastric cancer: diagnosis, genetic counseling, and prophylactic total gastrectomy. Cancer 2008;112:2655-2663.

29. Oliveira $C$, Velho $S$, Moutinho $C$, et al. KRAS and BRAF oncogenic mutations in MSS colorectal carcinoma progression. Oncogene 2007;26:158-163.

30. Bernards R, Weinberg RA. A progression puzzle. Nature 2002; 418:823.

31. Taniguchi K, Okami J, Kodama K, et al. Intratumor heterogeneity of epidermal growth factor receptor mutations in lung cancer and its correlation to the response to gefitinib. Cancer Sci 2008;99: 929-935.

32. Mateus AR, Seruca R, Machado JC, et al. EGFR regulates RhoAGTP dependent cell motility in E-cadherin mutant cells. Hum Mol Genet 2007;16:1639-1647.

33. Sawada K, Mitra AK, Radjabi AR, et al. Loss of E-cadherin promotes ovarian cancer metastasis via alpha 5-integrin, which is a therapeutic target. Cancer Res 2008;68:2329-2339.

34. Kawajiri $\mathrm{H}$, Yashiro $\mathrm{M}$, Shinto $\mathrm{O}$, et al. A novel transforming growth factor \{beta\} receptor kinase inhibitor, A-77, prevents the peritoneal dissemination of scirrhous gastric carcinoma. Clin Cancer Res 2008;14:2850-2860.

35. Kaurah P, MacMillan A, Boyd N, et al. Founder and recurrent $\mathrm{CDH} 1$ mutations in families with hereditary diffuse gastric cancer. JAMA 2007;297:2360-2372.

36. Brooks-Wilson AR, Kaurah P, Suriano G, et al. Germline E-cadherin mutations in hereditary diffuse gastric cancer: assessment of 42 new families and review of genetic screening criteria. J Med Genet 2004;41:508-517.

37. Suriano G, Yew S, Ferreira P, et al. Characterization of a recurrent germ line mutation of the E-cadherin gene: implications for genetic testing and clinical management. Clin Cancer Res 2005; 11:5401-5419.
38. Frebourg $\mathrm{T}$, Oliveira $\mathrm{C}$, Hochain $\mathrm{P}$, et al. Cleft lip/palate and $\mathrm{CDH} 1 / \mathrm{E}$-cadherin mutations in families with hereditary diffuse gastric cancer. J Med Genet 2006;43:138-142.

39. Oliveira C, Ferreira P, Nabais S, et al. E-cadherin (CDH1) and TP53 rather than SMAD4 and caspase-10 germline mutations contribute to genetic predisposition in Portuguese gastric cancer patients. Eur J Cancer 2004;40:1897-1903.

40. Yabuta T, Shinmura K, Tani M, et al. E-cadherin gene variants in gastric cancer families whose probands are diagnosed with diffuse gastric cancer. Int J Cancer 2002;101:434-441.

41. Simões-Correia J, Figueiredo J, Oliveira C, et al. Endoplasmic reticulum quality control: a new mechanism of E-cadherin regulation and its implication in cancer. Hum Mol Genet 2008;17:3566-3576.

42. Suriano G, Oliveira C, Ferreira $P$, et al. Identification of $\mathrm{CDH} 1$ germline missense mutations associated with functional inactivation of the E-cadherin protein in young gastric cancer probands. Hum Mol Genet 2003;12:575-582.

Received June 13, 2008. Accepted February 26, 2009.

Reprint requests

Carla Oliveira, IPATIMUP, Rua Roberto Frias s/n, 4200-465 Porto, Portugal. Tel: (351) 225570700, e-mail: carlaol@ipatimup.pt; fax: (351) 225570799.

Acknowledgments

The authors thank Sónia Melo, Helena Silva Pereira, Fernanda Milanezi, and Bárbara Gomes for technical assistance on preparation of paraffin sections for DNA extraction and IHC analysis of E-cadherin; and Cintia Alves for the technical support on in/del analysis.

\section{Conflicts of interest}

The authors disclose no conflicts.

\section{Funding}

Supported by The Portuguese Foundation for Science and Technology (FCT) (Projects: POCTI/SAU-OBS/58111/2004 and PTDC/SAU-GMG/72168/2006; PhD grants: SFRH/BD/41223/2007HP, SFRH/BD/15241/2004-RK, SFRH/BD/30039/2006-RP; salary support from Program Ciência 2007-CO). 